Besnard, D. \& Bastien-Toniazzo, M. (1999). Expert error in troubleshooting: An exploratory study in electronics. International Journal of Human-Computer Interaction, 50, 391-405.

\title{
EXPERT ERROR IN TROUBLESHOOTIING: AN EXPLORATORY STUDY IN ELECTRONICS
}

\author{
Denis Besnard \& Mireille Bastien-Toniazzo \\ CREPCO UMR 6561, \\ CNRS \& Université de Provence, \\ 29 avenue Robert Schuman, \\ 13621 Aix en Provence, France.
}

besnard@newsup.univ-mrs.fr ; bastien@newsup.univ.mrs.fr.

\begin{abstract}
It is known that novices show poor problem-solving performances and that they engage in a relatively insufficient inferential reasoning mode. Experts show high performances in routine situations in which they only activate knowledge. The main purpose of this work was to test the hypothesis that, under some conditions, novices may develop a more efficient diagnostic reasoning than experts, i.e. they may discover the cause of a faulty system conducting fewer tests while avoiding fixation errors. This hypothesis mainly relies on the possibility that experts may be victims of their own knowledge format (French and Sternberg, manuscript). It is tested in a faulty electronic circuit troubleshooting task. Data suggest that novices perform better than experts. Results are discussed with reference to the concepts of schema and expert error.
\end{abstract}




\section{THEORY}

\subsection{Expertise}

Expertise is a concept related to the state of a subject's knowledge in a familiar domain. It is supported by a context-specific knowledge format (e.g. a schema) that allows the cognitive system, provided with the necessary data, to produce reliable outcomes with a reduced load. Expertise reduces information processing load and allows the expert to cope with a possible increase (Bisseret, 1970). After intensive practice, automated processes are sufficient to process a task by associating a response to a situational cue (Rasmussen, 1986, 1993; Fink \& Lusth, 1987). Practice also reduces the number of steps in problem solving and reduces the time it takes to carry out each step (Carlson, Khoo \& Yaune, 1990). This processing automatization allows the expert to free the capacity of the working memory (Baddeley, 1992).

Expertise produces effects on memorization abilities (Chase \& Simon, 1973). Among experts, these abilities may be based upon a redistribution of the roles of short-term memory (STM) and long-term memory (LTM) that generates a long-term working memory (Ericsson \& Staszewski, 1989; Ericsson \& Kintsch, 1995). These abilities may also rely on frequently encountered situations specific memory structures (Boshuizen, Hobus, Custers \& Schmidt, 1991; Mumma, 1993; Gobet \& Simon, 1996a, 1996b; Custers, Boshuizen \& Schmidt, 1996). When the situation is recurrent, experts can store more information than novices. This mnemonic capacity difference relies on the encoding efficiency of relevant information (Wiedenbeck and Fix, 1993) rather than on an ability to process general information (Hunt, 1992): situational structural changes disrupt expert storage (Barfield, 1986; Norman, Brooks \& Allen, 1989; Frensch \& Sternberg, manuscript).

Chase \& Simon (1973) showed that if information could not be linked with a knowledge structure (e.g. in random chess game configurations), then expert recall performance falls to the level of novices. Violations in software programming conventions produce the same type of results among programmers (Soloway, Adelson \& Ehrlich, 1988). Some authors have suggested that experts' processing may rely on the problem structure, whereas novices' processing may be influenced by its form (Hardiman, Dufresne \& Mestre, 1989; Smith, 1992; Zajchowski \& Martin, 1993).

Our position is that experts and novices use surface features for solving problems. The difference relies on how they use them, i.e. what type of knowledge these features activate. In the case of novices, surface features activate an inferential processing whereas among experts, these surface features trigger task-specific complex knowledge structures: schemata. A schema is a stored knowledge structure that comprises sequences of steps (Detienne, 1996). It is a knowledge block which contains information and how to use it. It comprises an application domain defined by the activators it needs to be triggered. It also comprises a procedure composed of an instantiable plan that depends on the current situation requirements. It both enables relevant information search and the production of information when some of the situational data is missing (Van Eslande, 1992; Hunt, 1992). Schemata are not equal in weight. They have a specific threshold value from which they can be triggered. Some of these that have been recently and frequently used in a given context tend to maintain a higher triggering potential than those that have been activated less frequently in previous similar situations. Schemata allow fast processing of daily life stereotyped situations for which one could act in a quasi-automated mode based on an over-learned identification 
(Konradt, 1995). This may lead to biases in unfamiliar situations that share surface features with a familiar situation. This is the core of the theoretical hypothesis. It will be further exposed later.

\subsection{Error in diagnosis}

The human cognitive system structure implies that errors are liable to occur. The nature of these errors differ relatively to the type of implied knowledge and to the subject's competence level. There are many factors that determine errors. Human resources boundaries and problem complexity are only two of these.

Every human action is governed by the complex interaction of two control modes. The attentional mode (a), controlled by feedback, is slow, costly, limited, sequential and hard to conduct. The automatic mode (b) has no known limits and allows fast information processing, parallely ${ }^{1}$. When confronted with a symptoms pattern in a complex environment, the subject has too many concurrent hypotheses to reason sequentially in order to locate a potential cause of the problem. Complexity, especially if the problem is unknown, becomes a serious potential factor in limitation of resources. Complexity may be a feature of the system (Rouse $\&$ Rouse, 1979) and cause a decrease in diagnosis performance as the number of components and connections increases (Sanderson, 1990) or may be linked to the diversity of encountered situations (Amerge \& Mariné, 1992) or to a retro-action delay (Das, Jone \& Wong, 1990; Hoc, 1996). With the aim to avoid these problematic situations, operators use intuitive strategies (Rouse, 1978) and implement automated procedures primarily, when they are available.

Faults can only be detected from their observable symptoms (Reed \& Johnson, 1993). Another constraint is the difficulty to process extracted information in order to perform the diagnosis (Sanderson \& Murtagh, 1990). As the diagnosis process implies the implementation of automated procedures, symptoms extraction may be biased by symptoms frequency and by their saliency in the environment. Experts are the most liable subjects to this type of error as they emphasize frequency in symptoms extraction.

Experts in diagnosis (e.g. troubleshooters, physicians) recognize specific data patterns and use compiled rules and response plans (Gaba, 1991). This problem-solving method is used by subjects who have experienced a large number of problems in a specific task (Reed \& Johnson, 1993). In expert diagnosis, fault hypotheses are generated by mapping symptoms to knowledge. Rasmussen (1993) calls symptomatic strategy the process of automatically activating fault causes from symptoms. Experts rapidly activate information, and only the one that is relevant for the current case. Diagnosis is orientated towards a set of elements that may contain the fault (Nooteboom \& Leemeijer, 1993). However, in some situations such as detection of an unknown fault cause where usual symptom patterns are absent, experts cannot rely on this reasoning mode. The operator thus has to cease implementing usual strategies and develop inferences chains in order to reach the goal (Richard, 1990; Konradt, 1995). This is called topographic strategy (Rasmussen, 1986, 1993). In diagnosis, ceasing to use a heuristic strategy indicates the end of the automated control mode. Shifting to inference in order to process diagnosis leads experts to use a high cost reasoning mode they seldom use and that they reserve for unfamiliar situations or situations that imply an analytic reasoning mode

1 Parallel processing probably relies on time-sharing processes. One may however admit that some motor activities are performed during the execution of essentially cognitive processing as in the case of typewriting (Gentner, 1988). 
(Amalberti, 1992).

Troubleshooting expert operations are based upon intuitive probabilities. When an operator detects symptoms, he or she activates test procedures of some system element liable to explain symptoms. One may think that these procedures are scrolled from the least probable to the most probable (Bereiter \& Miller, 1989). The rules used during reasoning are selected on the basis of their implementation frequency. Each rule is associated to a strength that reflects its past usage (Anderson, 1993). While developing expertise, the rule becomes more and more specialized. It becomes active in an ever decreasing number of cases and through experience, it becomes activated only in situations where the action it refers to is the correct procedure (Ohlsson, 1996). Operators are fallible statisticians (Patrick, 1993) and frequencybased activation may generate errors. In a routine fault situation, the most frequent cues are recognized rapidly and a pattern emerges even if all the symptoms have not been discovered (Hoc, 1996). Diagnosis may be processed with incomplete cues. This is the typical expert error. It is due to an automated and incomplete symptoms detection.

Experts efficiency in routine problem solving is a well-known phenomenon. Some researchers have shown that experts are sensitive to structure changes (Chase \& Simon, 1973; Frensch \& Sternberg, manuscript) when they solve problems. In this research, we will attempt to demonstrate that expert problem solving does not only rely on structural features [contrary to the position of Hardiman et al. (1989), Smith (1992) Zajchowski and Martin (1993)] and that surface features play a central role.

Experts implement heuristics, schemata and executable problem-solving strategies. They conduct their activity on the automated mode. In a routine problem solving, experts launch a schema on the basis of situational cues. Schemata accept rough cues and may trigger a series of irrelevant actions for the current task (Reason, 1993). If the situational activators of a routine task cause the expert to launch a salient or frequent schema, then this subject may ignore complementary cues and may launch an irrelevant schema. Although it cannot be excluded that experts do implement inferences while solving problems, we have focused on the possibility that these subjects can persevere in the activated schema. In the type of situation studied here, the expert may persevere in the activated schema. Sanderson and Murtagh (1990) showed this phenomenon in a diagnosis task of a formal network. Subjects have difficulties in considering a cause other than the one hypothesized, even if cues in the situation suggest that it is not the most acute hypothesis. This error is called fixation error: when a schema is activated in the context of a symptomatic strategy, the expert cannot return to a topographic strategy and he or she fixes on the knowledge that has already been activated.

In the studied task ${ }^{2}$, one makes the assumption that the novice should have fewer difficulties than the expert. The novice reasons on a controlled mode and problems are solved by a sequence of inferences, by a knowledge-based reasoning, not by a [symptom $\rightarrow$ fault] association. The surface features he or she extracts do not launch a schema but are used to build a representation of the fault and the produced inferences allow him or her to test more diversified hypotheses than experts.

In other words, when diagnosing a fault in an electronic system, the expert applies a schema whereas the novice makes inferences. Contrary to expert procedure, the novice does not emphasize a particular component as his or her knowledge does not allow to sort the frequency of faults. In the case of a fault in an electronic circuit (our task), we expect novices' diagnosis process to be indifferently directed towards active components (integrated circuits)

2 A troubleshooting task in an electronic circuit. 
and passive components (e.g. resistances, condensers, switches).We also expect novices to find the cause of the fault in fewer tests than experts. This prediction relies partly on the idea that experts may be victims of their format of knowledge (Frensch \& Sternberg, manuscript). This hypothesis could be considered as a weak one for it is known that prior knowledge may be a constraint on reasoning activities. One could talk about ossified knowledge among experts that inhibit flexibility. But our hypothesis is rather non-intuitive if one considers that novices can exhibit better performances than experts. As far as we know, that kind of hypothesis is not much documented.

\section{METHOD}

In order to test the hypothesis of a better diagnosis by novices, a troubleshooting task is created. The fault is implemented in an amplification circuit. Its originality lies in the fact that its frequency is very low but its symptoms are very close to the symptoms of a frequent fault.

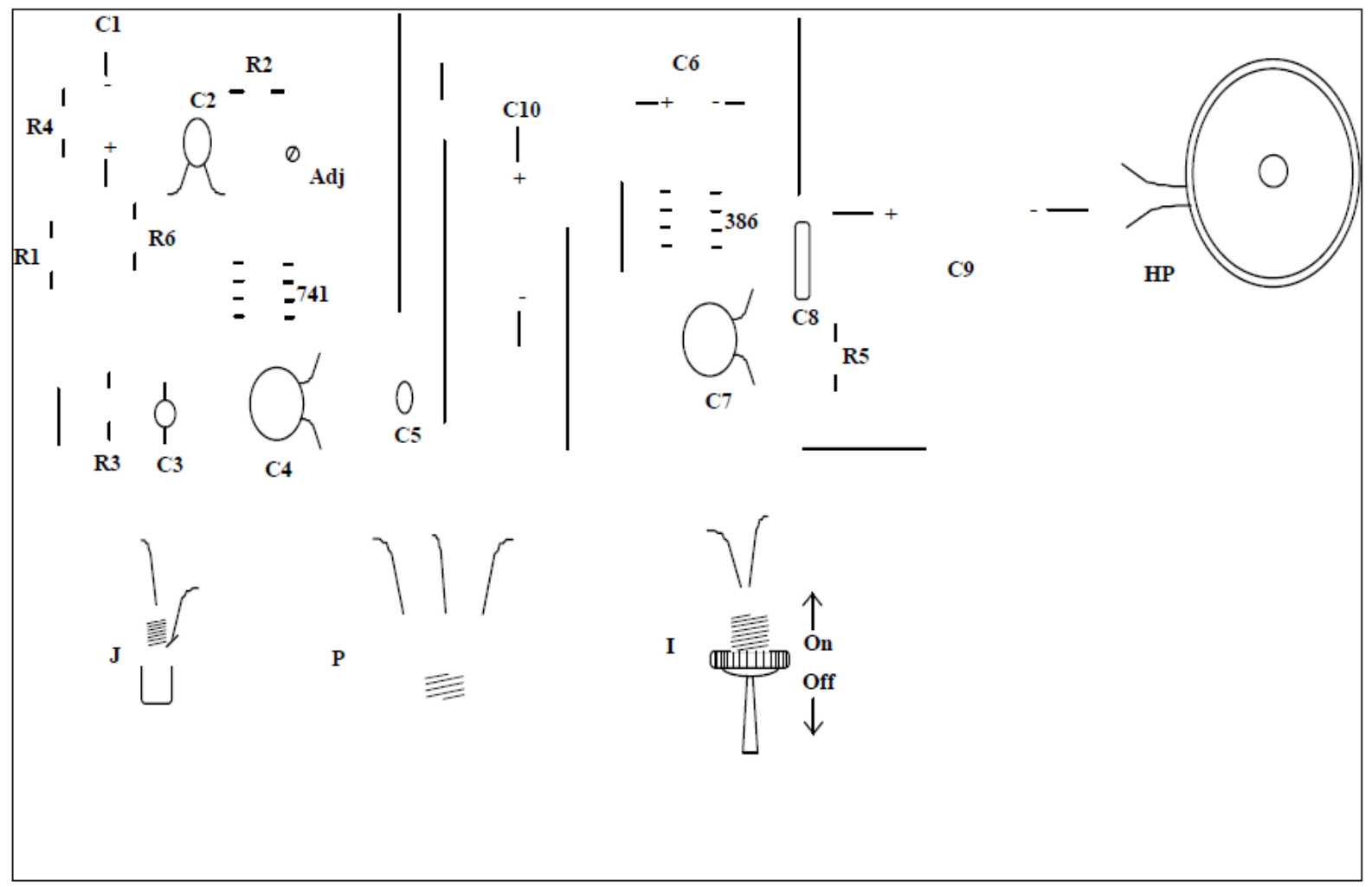

FIGURE 1. Implantation schema.

\subsection{Subjects}

The subjects are three novices and three experts in electronics. Novices are male bachelor students of a technical school. These subjects have been studying electronics for two years. Experts are male professional operators in electronics that have between 19 and 20 years of experience.

The low number of subjects is explained by the exploratory aim of the study and by the difficulty to recruit professional troubleshooters. 


\subsection{Materials}

In order to process the troubleshooting task, the subjects use conventional tools (multimeter, oscilloscope) and implantation and theoretical schemata. The implantation schema (Figure 1) is a representation of the topographic aspect of the circuit that comprises the names of the components. The theoretical schema (Figure 2) represents the connections and the names of the components.

\subsection{Apparatus}

The system ${ }^{3}$ is a simple low-frequency amplifier. The assembling of the circuit, its schemata and components conform to conventions. It has no hidden elements. Schemata correspond to the assembly. The board on which the circuit is assembled allows subjects to visualize the tracks and the connections between the components.

\subsection{Fault description}

The fault is similar to another fault the diagnosis of which is rapid: an integrated circuit (IC) failure. The fault is on C7 condenser (cf. implantation schema). This component is in shortcircuit due to a thin invisible weld wire 4 .

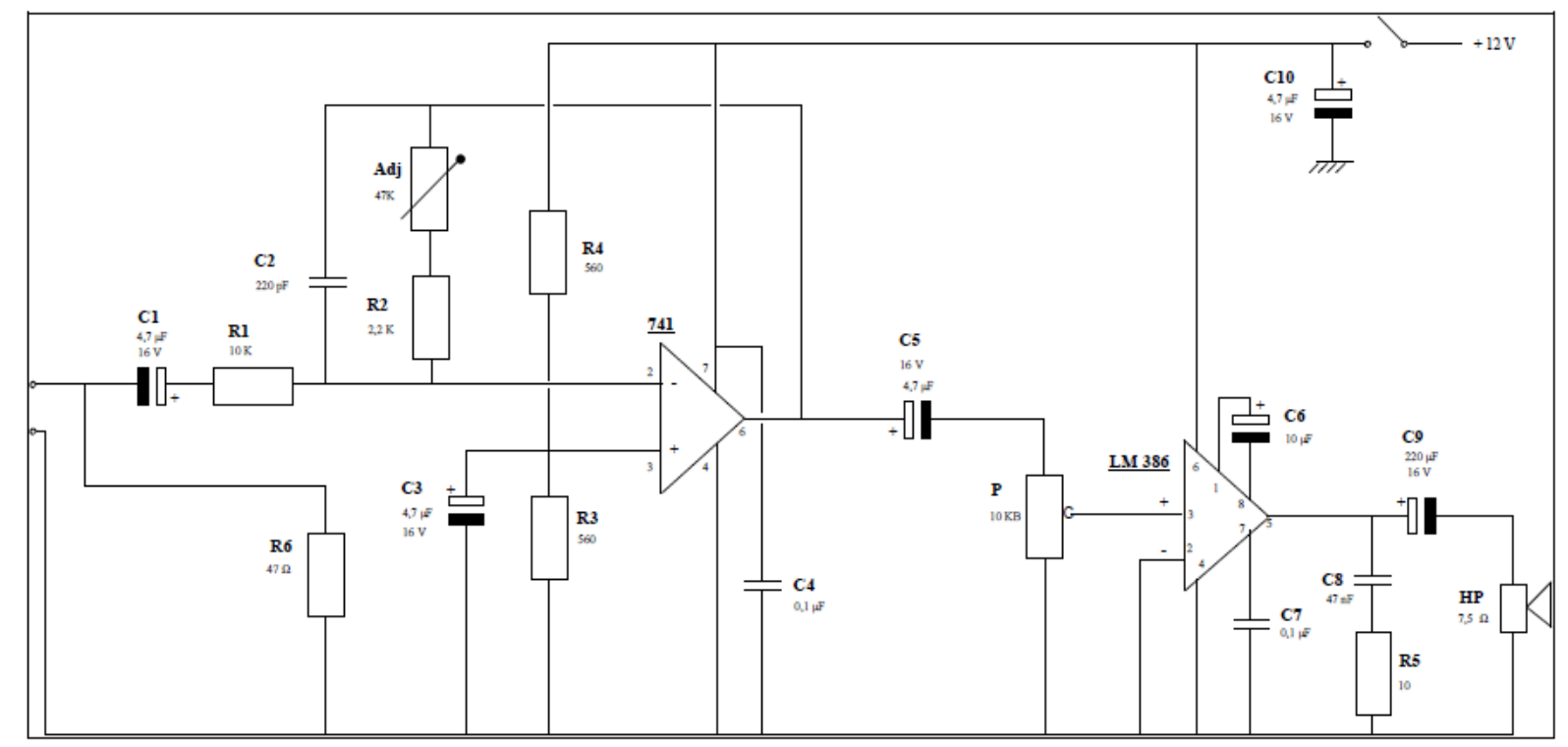

FIGURE 2. Theoretical schema.

3 The authors wish to thank Jean Claude GEDIN (CREPCO) for the design of the circuit.

4 This wire simulates the fault of this component (C7) for it was physically impossible to damage it, even by connecting it to a $220 \mathrm{~V}$ AC. 


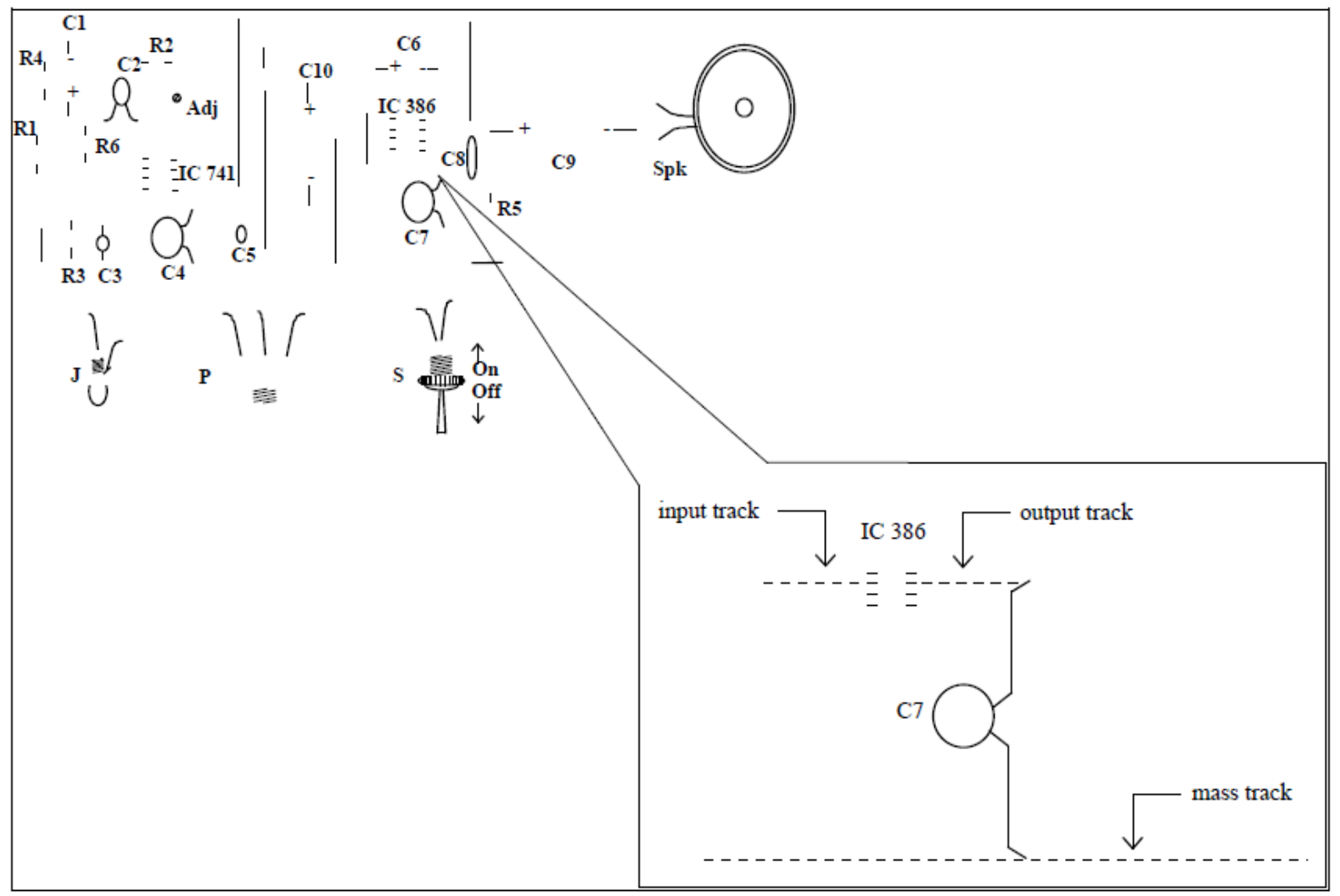

FIGURE 3. Fault description.

The produced symptoms lead to suspect the connected IC as the cause of the fault. In normal conditions (i.e. without a faulty C7), IC386 receives the electric signal on the input pin, and restitutes it on the output pin, as showed in Figure 3.

\subsection{Procedure}

The subject is installed at a conventionally equipped (e.g. multimeter, oscilloscope) post. After the instructions are read to the subject, he or she is introduced to the system, and the troubleshooting task begins. The tests are noted on a grid (cf. the appendix). The subject may replace components.

The diagnosis stops when the subject finds the faulty component or when he believes that all the alternatives have been eliminated. The only questions the experimenter answers refer to intervention requests.

\subsubsection{Instructions}

The experiment takes place at the work place of the subject, in a measure laboratory. The subject is installed at a post and the experiment is presented.

I am going to ask you to troubleshoot a low-frequency amplifier. It is faulty at the moment. I want you to identify the cause of that fault. In order to proceed, you may use any measure tool. You may also use implantation and theoretical schemata. These are exact schemata and they correspond to the connections and locations of the components of the circuit. Each time you wish to test a 
component, you must give me its name as written on the schemata. After each test, you must tell me whether you deduce anything. You must always say something after a test. Even if you deduce nothing, you must tell me so.

I have a limited knowledge in electronics. That is why I ask you to speak during diagnosis, to "think aloud" as if I could see what you are thinking about so that I can understand what you do. You cannot touch the components except with measure instruments. If you have any intervention to perform on the circuit, you must ask me to, and I will do it.

\subsection{Plan of experiment and variables}

The plan is $\mathrm{S} 3<\mathrm{E} 2>$ where $\mathrm{E}$ is experience, with two modalities (expert vs. novice).

Eight dependent variables were retained. Only five support the discussion. They were calculated from three other secondary variables. All the variables concern three kinds of indicators: number of tests, tests repetitions and IC tests. These indicators provide information about diagnosis length in terms of number of steps, fixation errors and which component is concerned by these errors, respectively.

\subsubsection{Secondary dependent variables}

Number of tests of IC386. The value of this variable reflects the importance of this component in the diagnosis process. It is the mean number of tests of IC386. This variable comprises isolated and chained-tests ${ }^{5}$. It is used to calculate dependent variable number 1.

Number of tests before a test of an IC. The value of this variable indicates how soon IC tests are performed in the diagnosis process. This variable refers to the number of tests the subject performs before a first test of an IC. It is used to calculate dependent variable number 2 .

Number of tests before a test of IC 386. The value of this variable indicates how soon IC386 tests are performed in the diagnosis process. This variable refers to the number of tests the subject performs before a first test of IC386. It is used to calculate dependent variable number 3.

\subsubsection{Main dependent variables (DV)}

DV 1. Percentage of tests of IC386: this variable refers to the proportion of tests of IC386. It deals with the centrality of this component in the diagnosis process.

DV 2. Progression of diagnosis before a test of an IC: this variable refers to the proportion before a first test of an IC. It deals with the centrality of this category of components in the diagnosis process.

DV 3. Progression of diagnosis before a test of IC386: this variable refers to the proportion of tests performed before a first test of IC386. It deals with the centrality of this component in the diagnosis process.

5 A definition of a chained test will be given during the presentation of the variables. 
DV 4. Number of chained tests of IC386. tests are said to be chained when they are performed in a sequence without being inserted in a split-half ${ }^{6}$. This variable refers to the importance of fixation errors.

DV 5. Number of tests: it is the mean number of tests performed by each group of subjects. This variable refers to diagnosis length in terms of steps.

\section{PREDICTIONS}

As secondary dependent variables are used for calculation purposes only, the predictions concern main dependent variables.

If situational cues allow the expert to launch a schema, then the information that does not match the schema will probably be neglected. If the activated schema does not allow one to find the cause of the fault, it must be revised or abandoned. Calling the schema into question is slowed down by the expert's fixation to the implemented strategy. This fixation is assumed to be at the origin of the expected difference in performance between experts and novices.

We expect experts to perform proportionally more tests of IC386 (DV number1) than novices for (a) it is a central component in the system and for (b) it often fails. Experts should perform less tests than novices before testing an IC (DV number 2) for this type of component often fails. IC386 is especially concerned by this prediction (DV number 3). Experts, due to fixation errors, should perform more chained tests of IC386 (DV number 4) than novices. Novices should globally perform less tests than experts for their diagnosis process should not be disrupted by fixation errors.

TABLE 1. Summary of the results

\begin{tabular}{lcc}
\hline \multicolumn{1}{c}{ Dependent variables } & Novices & Experts \\
\hline Percentage of tests of IC386 & 15.38 & 47.45 \\
Progression of diagnosis before a test of an IC (\%) & 23.07 & 3.03 \\
Progression of diagnosis before a test of IC386 (\%) & 35.38 & 14.23 \\
Number of chained tests of IC386 & 0 & 5.36 \\
Mean number of tests & 13 & 39.33 \\
\hline
\end{tabular}

6 This method consists in splitting the set of the components by an appropriate test (Patrick, James \& Friend, 1996). The optimal strategy consists, after having tested component $X$ and having measured its malfunctioning, in modifying the state of a component that may have effects on $\mathrm{X}$ and processing a new test of X. 


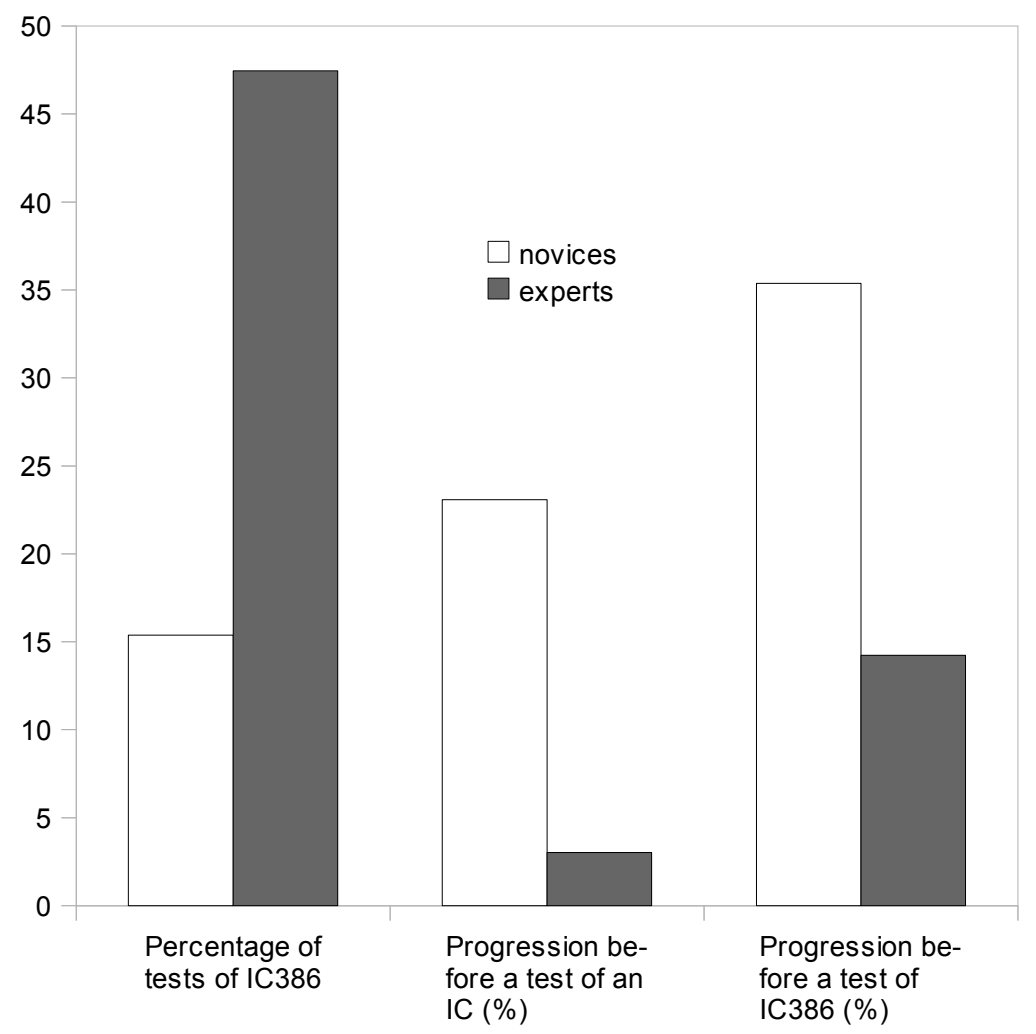

FIGURE 4. Percentage of tests of IC386 (DV 1), progression before a test of an IC (DV 2) and progression before a test of IC386 (DV 3) as a function of the level of expertise (percentages).

\subsection{Results}

This research is an exploratory study. The low number of subjects only allows us to test an assumption and to measure tendencies. The analysis that is conducted is rather qualitative. No analysis of variance was conducted. Only the main dependent variables are presented in Table 1 and in Figures 4 and 5.

One novice did not find the cause of the fault. He nonetheless was included in the data analysis for we are more interested in the implemented strategies than in the strict identification of the fault. Experts performed three times more tests than novices to find the cause of the fault (experts $=39.33$; novices $=13$ ). They performed more tests of IC386 than novices (experts $=18.66$; novices $=2$ ). Experts performed chained tests of IC386 whereas novices did not (experts $=5.36$; novices $=0$ ). The nature of the symptoms (a condenser fault that looks like an IC386 fault) is the cause of this fixation behaviour. 


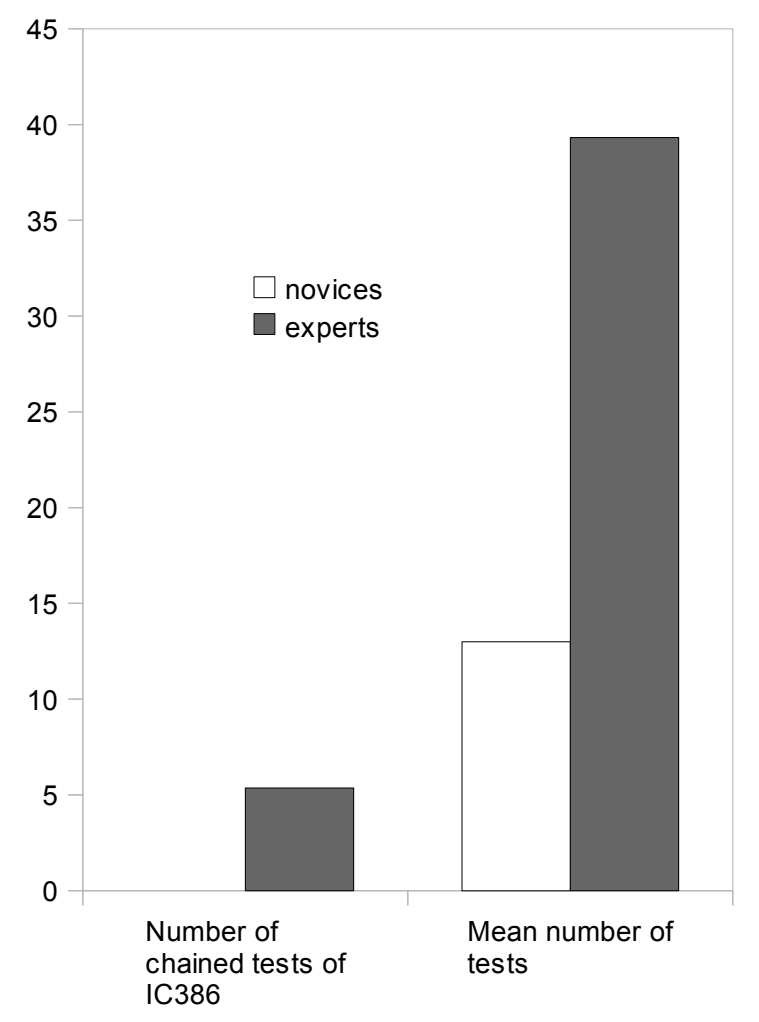

FIGURE 5. Number of chained tests of IC386 (DV 4) and mean number of tests (DV 5) as a function of the level of expertise.

Tests of IC386 represented an important part of diagnosis for experts (experts $=47.45 \%$; novices $=15.38 \%$ ) which reveals a difference in system representation. Experts performed the first IC test at an early stage of the diagnosis process (experts progression $=3.03 \%$; novices progression $=23.07 \%$ ). They also performed the first test of IC386 at an early stage of the diagnosis process $($ experts progression $=14.23 \%$; novices progression $=35.38 \%$ ). The latter results show the importance of the ICs in the diagnosis process. This kind of component usually explains the symptoms related to the fault.

\section{DISCUSSION}

Results do not contradict the hypotheses. Experts perform more tests than novices and rely strongly on ICs. They test these components early and repeatedly in the diagnosis process. IC386 is the key component of the diagnosis process. When trying to locate the fault, it is the first abnormally behaving component the expert encounters: it receives inputs but produces no output. Experts tend to develop a fixation on this component because of its centrality in the system and also because of the knowledge they have about its fragility. The frequency of fault is used by experts as a tool that guides the diagnosis process. The importance of this heuristic is broadly over-estimated by experts which, when the current fault is not the one that is expected, makes them produce fixations. 
A possible explanation of the results is that expert diagnosis relies on a probabilistic reasoning: "The fault finder might select the fault ${ }^{7}$ which has been most likely to give rise to the designated symptoms in the past" (Patrick, 1993, p. 193). During the diagnosis process, the expert extracts symptoms that play the role of activators. Once perceived, they guide the diagnosis process, making a schema apply. The prioritary schema among experts points IC386 as a good alternative for explaining the symptoms. These subjects, when faced with IC386 that has no output signal, apply the most frequent troubleshooting schema: IC386 failure. This is what Amalberti and Hoc (1993) call a "rough identification by comparing a known schema with observed facts" (p. 50).

The main result deals with the percentage of tests of IC386 among experts. It is much higher than among novices. In a strategic view, this difference may be explained by the implementation of a frequency heuristic. Our experts have about 20 years of experience. They have a lot of knowledge about electronics principles and also empirical knowledge about failures in the systems. The latter supports an economic strategy that incriminates ICs first. Novices have mainly declarative knowledge. This format does not allow them to associate symptoms to faults but only inferential processing. This sequential mode has disadvantages in complex or high temporal constrained tasks but it offers the advantage of not being liable to the frequency bias. The inferences that novices produce in the diagnosis process force them to consider the absence of output signal from IC386 as an information that is not relevant enough in order to locate the fault. They even seem to consider the absence of signal as a consequence of the fault whereas experts consider it as the cause. In the novices' minds, there is no priority component when they must attribute the cause of the fault, or at least, the criterion differs from that of the experts. The percentage of tests of IC386 reveals that their reasoning process is not a probabilistic one and that their strategy does not rely on the frequency of ICs failures.

At the end of task, subjects were informally asked to say what they thought about the fault. Experts said that the fault was difficult to find for $\mathrm{C} 7$ (a ceramic condenser) is very reliable and is very seldom at fault. They explain the importance of the IC386 in terms of difference of fault probability between an IC386 and a condenser. From that point of view, experts difficulties may be conceived as the sign of normal behaviour. It was hard for them to locate the fault because they are experts. In natural situations, one of the experts' strategies consists, after having tested the power supply, in testing ICs of the faulty circuit. This procedure agrees with the principle of economy: tests first involve active components which are responsible for most faults.

\section{CONCLUSION}

Experts identify the state of a component (IC386), measure no output signal and then activate the procedure that is necessary to replace this component. In the fault detection process, experts directly shift from observation of the oscilloscope data towards the replacement procedure. This problem-solving mode exhibits the absence of any controlled reasoning process. The component replacement procedure activation is the result of an automated association between a set of symptoms and the cause of a fault. It is a cause-to-effect link that experience has developed through empirical observations (Fink \& Lusth, 1987). In the case of novices, the identification of the abnormal behaviour of IC386 does not imply a replacement

7 That is, the cause of the fault (Chang, Di Cesare \& Goldbogen, 1991). 
decision but instead involves a search for causes of this behaviour and gathering of further information. These latter subjects implement a rather topographic strategy.

Reason relies on Rasmussen's (1986) model to analyse human error. At the level of automatisms, human activity is controlled by stored configurations of pre-programmed instructions. Errors at this level are whether the launch of a consistent behaviour at the wrong moment or place, or omissions. In this study, experts activate a replacement procedure. Performing many tests of the IC386 denotes difficulties for the formulation of another hypothesis. This type of error is very probable in our task for "the present environmental state conforms to past regularities" (Reason, 1993, p. 104).

A schema may accept rough specific activators (Reason, 1993). This is one of the features of action schemata in relation to cognitive economy and releasing of attentional capacity. One of the consequences is the launch of an irrelevant schema. The symptoms that experts extract are the ones that would permit an acute diagnosis in a routine situation (ceramic condensers ${ }^{8}$ virtually never fail) but not in the current one. The strength of the association between the symptoms and the fault lowers the necessity of an instantiation of the activated knowledge (Reason, 1993) and makes it more accessible (Anderson, 1993).

Lesgold, Glaser, Rubinson, Klopfer, Feltovitch and Wang (1988) showed that expert radiologists may produce less acute diagnoses than resident radiologists. The authors conclude that expertise is not a monotonic function of experience. It builds itself via fluctuations in the performance levels. The number of years of experience per se is not a nonfallible indicator of the performance level of an operator in his competence domain.

According to some authors, experts in a problem-solving situation rely on structural features whereas novices rely on surface features (Hardiman et al., 1989; Smith, 1992; Zajkowski and Martin, 1993). This dichotomy seems excessive. The results of this study show that experts rely on surface features. In the case of novices, surface cues support inferences. In the case of experts, the same surface cues launch automated processing. Both experts and novices use surface features. The difference relies in how they use them.

\section{REFERENCES}

AMALBERTI, R. \& HOC, J. M. (1993). Un modèle heuristique des liens entre planification, diagnostic et action: point de départ pour des recherches sur la résolution de problème en contrôle de processus. Actes du colloque de prospective Recherches pour l'ergonomie. Université de Toulouse-Le-Mirail (pp. 45-52).

AMALBERTI, R. (1992). Safety and process control: an operator-centered point of view. Reliability Engineering and System Safety, 38, 99-108.

AMERGE, C. \& MARINE, C. (1992). Etude comparative expert-débutant lors de l'élaboration d'un prédiagnostic ergonomique. Le Travail Humain, 55, 97-117.

ANDERSON, J. R. (1993). Problem solving and learning. American Psychologist, 48, 35-44.

BADDELEY, A. (1992). Is working memory working? The fifteenth Bartlett lecture. The Quartely Journal of Experimental Psychology, 44, 1-31.

BARFIELD,W. (1986). Expert-novice differences for software: implications for problemsolving and knowledge acquisition. Behaviour and Information Technology, 5, 15-29.

BEREITER,S. R. \& MILLER, S. M. (1989). A field-based study of troubleshooting in

8 Component $\mathrm{C} 7$ is a ceramic condenser. 
computer-controlled manufacturing system. IEEE Transactions on Systems, Man and Cybernetics, 19, 205-219.

BISSERET, A. (1970). Analyse de la mémoire opérationnelle du contrôleur de la navigation aérienne. Etude de l'Institut de Recherche d'Informatique et d'Automatique. Rocquencourt.

BOShuizen, H. P. A., HOBUS, P. P. M., CUSTERS, E. J. F.M. \& SCHMIDT, H. G. (1991). Cognitive effects of practical experience. In D. A. EVANS and V. L. PATEL (Eds.) Advanced Models of Cognition for Medical Training and Practice. Heidelberg: Springer Verlag (pp. 337-348).

CARLSON, R. A., KHOO, B. H. \& YAURE, R. G. (1990). Acquisition of a problem-solving skill: levels of organization and use of working memory. Journal of Experimental Psychology: General, 119, 193-214.

CHANG, S. J., Di CESARE, F. \& GOLDBOGEN, G. (1991). Failure propagation trees for diagnosis in manufacturing systems. IEEE Transactions on Systems, Man and Cybernetics, 21, 767-776.

CHASE, W. G. \& SIMON, H. A. (1973). Perception in chess. Cognitive Psychology, 4, 5581.

CUSTERS, E. J. F., BOSHUIZEN,H. P. A. \& SCHMIDT, H. G. (1996). The influence of medical expertise, case typicality and illness script component on case processing and disease probability estimates. Memory and Cognition, 24, 384-399.

DAS, S. R., JONE, W. B. \& WONG, K. L. (1990). Probability modeling and fault analysis in sequential logic using computer simulation. IEEE Transactions on Systems, Man and Cybernetics, 20, 490-498.

DETIENNE, F. (1996). What models for program understanding? Actes du colloque. Processing complex Information. Université de Poitiers (pp. 60-66).

ERICSSON, K. A. \& KINTSCH, W. (1995). Long term working memory. Psychological Review, 102, 211-245.

ERICSSON, K. A. \& STASZEWSKI, J. (1989). Skilled memory and expertise: mechanisms of exceptional performance. In D. KLAHR and K. KOTOVSKY (Eds.) Complex Information Processing. Hillsdale, NJ: Lawrence Erlbaum.

FINK, P. K. \& LUSTH, J. C. (1987). Expert systems and diagnostic expertise in the mechanical and electrical domains. IEEE Transactions on Systems, Man and Cybernetics, 17, 340-349.

FRENSCH, P. A. \& STERNBERG, R. J. Expertise and flexibility: the costs of expertise. Manuscript.

GABA, D. (1991). Dynamic decision making in anesthesiology: Cognitive models and training approaches. In D. A. EVANS \&V. L. PATEL (Eds.) Advanced Models of Cognition for Medical Training and Practice. Heidelberg: Springer-Verlag (pp. 123147).

GOBET, F. \& SIMON, H. A. (1996a). Templates in chess memory: a mechanism for recalling several boards. Cognitive Psychology, 31, 1-40.

GOBET,F . \& SIMON, H. A. (1996b). Recall of random and distorted chess positions: implications for the theory of expertise. Memory and Cognition, 24, 493-503.

HARDIMAN, P. T., DUFRESNE, R. \& MESTRE, J. (1989). The relation between problem categorization and problem solving among experts and novices. Memory and 
Cognition, 17, 627-638.

HOC, J. M. (1996). Supervision et contrôle de processus. La cognition en situation dynamique. Grenoble: PUG.

HUNT, E. (1992). Why is it hard to improve mental competence? A cognitive science perspective. Advances in Cognition and Educational Practice, 1A, 3-24.

KONRADT, U. (1995). Strategies of failure diagnosis in computer-controlled manufacturing systems: empirical analysis and implications for the design of adaptive decision support systems. International Journal of Human-Machine Interaction, 43, 503-521.

LESGOLD, A., GLASER, R., RUBINSON, H., KLOPFER, D., FELTOVITCH, P. \& WANG, Y. (1988). Expertise in a complex skill: diagnosing X-ray pictures. In M. T. H. CHI, R. GLASER and M. J. FARR (Eds.) The Nature of Expertise. Hillsdale, NJ: Lawrence Erlbaum.

MUMMA, G. H. (1993). Categorization and rule induction in clinical diagnosis and assessment. The Psychology of Learning and Motivation, 29, 283-326.

NOOTEBOOM, P. \& LEEMEIJER, G. B. (1993). Focusing based on the structure of a model in model-based diagnosis. International Journal of Man-Machine Studies, 38, 455474.

NORMAN, G. R., BROOKS, L. R. \& ALLEN, S. W. (1989). Recall by expert medical practitioners and novices as a record of processing attention. Journal of Experimental Processing: Learning, Memory and Cognition, 6, 1166-1174.

OHLSSON, S. (1996). Learning from performance errors. Psychological Science, 103, 241262.

PATRICK, J. (1993). Cognitive aspects of fault-finding training and transfer. Le Travail Humain, 56, 187-209.

RASMUSSEN, J. (1986). Information Processing and Human-Machine Interaction. Amsterdam: Elsevier.

RASMUSSEN, J. (1993). Diagnostic reasoning in action. IEEE Transactions on Systems, Man and Cybernetics, 23, 981-992.

REASON, J. (1993). L'erreur humaine. Paris: PUF (original edition: Human Error (1990)). Cambridge: Cambridge University Press.

REED, N. E. \& JOHNSON, P. E. (1993). Analysis of expert reasoning in hardware diagnostic. International Journal of Man-Machine Studies, 38, 251-280.

RICHARD, J. F. (1990). Les activités mentales. Paris: PUF.

ROUSE, W. B. (1978). Human problem solving performance in a fault diagnosis task. IEEE Transactions on Systems, Man and Cybernetics, 8, 258-271.

ROUSE, W. B. \& ROUSE S. H. (1979). Measures of complexity in fault diagnosis tasks. IEEE Transactions on Systems, Man and Cybernetics, 9, 720-727.

SANDERSON, P. M. (1990). Knowledge acquisition and fault diagnosis: experiments with PLAULT. IEEE Transactions on Systems, Man and Cybernetics, 20, 255-242.

SANDERSON, P. M. \& MURTAGH, J. M. (1990). Predicting fault diagnosis performance: why are some bugs hard to find? IEEE Transactions on Systems, Man and Cybernetics, 20, 274-283. 
SMITH, M. U. (1992). Expertise and the organization of knowledge: unexpected differences among genetic counselors, faculty, and students on problem categorization tasks. Journal of Research in Science Teaching, 29, 179-205.

SOLOWAY, E., ADELSON, B. \& EHRLICH, K. (1988). Knowledge and processes in the comprehension of computer programs. In M. T. H. CHI, R.GLASER \& M. J. FARR, (Eds.) The Nature of Expertise. Hillsdale, NJ: Lawrence Erlbaum.

VAN ESLANDE, P. (1992). Les erreurs d'interprétation en conduite automobile: mauvaise catégorisation ou activation erronée de schémas? Intellectica, 15, 125-149.

WIEDENBECK, S. \& FIX, V. (1993). Characteristics of the mental representations of novice and expert programmers: an empirical study. International Journal of Man-Machine Studies, 793-812.

ZAJCHOWSKI, R., \& MARTIN, J. (1993). Differences in the problem-solving of stronger and weaker novices in physics: knowledge, strategies, or knowledge structure? Journal of Research in Science Teaching, 30, 459-470.

\section{APPENDIX}

Tests recording grid

\begin{tabular}{|c|c|c|c|c|c|c|c|c|c|c|c|c|c|c|c|c|c|c|c|c|}
\hline & 1 & 2 & 3 & 4 & 5 & 6 & 7 & 8 & 9 & 10 & 11 & 12 & 13 & 14 & 15 & 16 & 17 & 18 & 19 & 20 \\
\hline \multicolumn{21}{|l|}{$\mathrm{HP}$} \\
\hline \multicolumn{21}{|l|}{1} \\
\hline \multicolumn{21}{|l|}{$\mathrm{P}$} \\
\hline \multicolumn{21}{|l|}{$\mathrm{J}$} \\
\hline \multicolumn{21}{|l|}{ Tsfo } \\
\hline \multicolumn{21}{|c|}{ Radio } \\
\hline \multicolumn{21}{|c|}{ Cordon } \\
\hline \multicolumn{21}{|c|}{$\mathrm{Cl}$} \\
\hline \multicolumn{21}{|l|}{ C2 } \\
\hline \multicolumn{21}{|l|}{ C3 } \\
\hline \multicolumn{21}{|l|}{ C4 } \\
\hline \multicolumn{21}{|l|}{ CS } \\
\hline \multicolumn{21}{|l|}{ C6 } \\
\hline \multicolumn{21}{|l|}{$\mathrm{C} 7$} \\
\hline \multicolumn{21}{|l|}{ C8 } \\
\hline \multicolumn{21}{|l|}{ C9 } \\
\hline \multicolumn{21}{|l|}{$\mathrm{ClO}$} \\
\hline \multicolumn{21}{|l|}{$\mathrm{RI}$} \\
\hline \multicolumn{21}{|l|}{ R2 } \\
\hline \multicolumn{21}{|l|}{ R3 } \\
\hline \multicolumn{21}{|l|}{ R4 } \\
\hline \multicolumn{21}{|l|}{ R5 } \\
\hline \multicolumn{21}{|l|}{ R6 } \\
\hline \multicolumn{21}{|l|}{741} \\
\hline \multicolumn{21}{|l|}{386} \\
\hline Adi & & & & & & & & & & & & & & & & & & & & \\
\hline
\end{tabular}

